\title{
Tipografia tátil
}

\section{Tactile typography}

\author{
Luciana Eller Cruz \\ Universidade de Brasília, Brasil \\ Lucianaeller14@gmail.com \\ Ana Claudia Maynardes \\ Universidade de Brasília, Brasil \\ anacmay@gmail.com
}

\begin{abstract}
This paper reports an academic experimental research conducted at the University of Brasilia. The goal of this study is to develop a product that allows to mitigate the restricted access to visual content such as the study of typography for vision impaired people. Plaques were constructed with input letters in different typefaces making a two-dimensional shape into a three-dimensional object that can be perceived haptically. The modules were presented to visually impaired people who identified the specific characteristics presented.
\end{abstract}

Keywords: Tipografia; prototipagem; acessibilidade; educação.

\section{Introdução}

O presente artigo relata uma pesquisa experimental acadêmica desenvolvida na Universidade de Brasília, Curso de Design, na Disciplina de Projeto de Produto 2. O objetivo era, a partir do tema "acessibilidade", desenvolver um produto que permitisse resolver ou amenizar o restrito acesso a conteúdos visuais como, por exemplo, o estudo da "tipografia", por pessoas com deficiência visual ou baixa visão.

A pesquisa experimental consistiu em desenvolver objetos em relevo ou tridimensionais, a partir da prototipagem rápida, que permitissem, por meio do toque, uma correta identificação das características anatômicas e estilísticas das fontes tipográficas, com o intuito de se criar uma ação pedagógica para que os deficientes visuais pudessem compreender as nuanças e sutilezas da variedade existente de fontes tipográficas da escrita latina e entender os seus significados formais e históricos.

\section{Antecedentes}

O uso do alfabeto latino como conhecemos hoje, tem origens remotas que surgiram da necessidade do homem de criar registros, armazenar dados e se comunicar. Inicialmente a escrita era formada por ideogramas, posteriormente passou a adquirir valores fonéticos, reduzindo também a necessidade de signos para traduzir as ideias de um idioma. O alfabeto passa a existir a partir da decomposição da palavra em sons simples, e nele foram incorporados os sons vocálicos. Assim, o alfabeto passa a ser dividido em consoantes e vogais.

Segundo Kane (2003), atualmente o design de tipos ou tipográfico possui uma enorme variedade de fontes que se multiplicam em famílias tipográficas, que congregam muitas variações de um determinado desenho. A mais frequente reúne os estilos regular (romano), negrito, itálico e negrito itálico. Também existem famílias com diferentes variantes intermediárias, com diversas opções de peso (leve, médio, regular, semi-negrito, negrito, extra-negrito) e de larguras (comprimido, condensado, normal, estendido, alargado, entre outros).

Tanto em sua dimensão construtiva, quanto na dimensão projetiva, a disciplina de design (design de produto ou design gráfico) sempre teve como premissa que 0 ato de compreender traria consigo o ato de ver.

A construção de uma página de livro, de uma marca de empresa ou no campo da sinalização, dentro da concepção do design gráfico, utiliza a tipografia para expressar ou informar seus conteúdos e sinalizar suas formas. O uso da tipografia, além de permitir a comunicação pura, permite também a expressão de uma ideia, de um conceito.

A fruição ou a experiência de uma pessoa com deficiência visual, ao se deparar com um símbolo de uma empresa composto por tipos ou tipos estilizados torna-se inviável sem o conhecimento conceitual e formal aos quais a tipografia utilizada remete.

Há inúmeras empresas que constituem suas identidades visuais por meio do uso e aplicação de diferentes fontes tipográficas, como por exemplo, a Volkswagen, que utiliza o "v" e o "w" dentro de um círculo, no qual o "v" é parte do "w"; ou a Toyota, que utiliza um grid de formas ovais, para formar o desenho de suas letras e a junção de todas as formas constrói o símbolo em "T". 


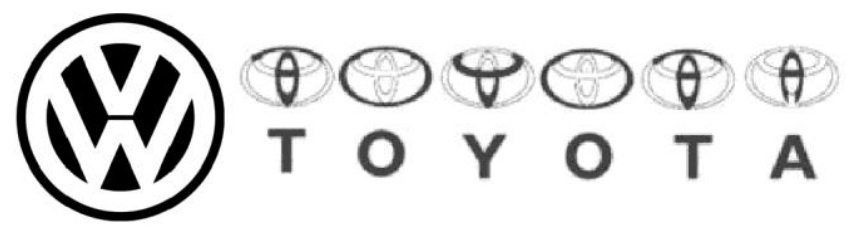

Figura 1: Símbolos de grandes marcas de empresas que utilizam tipografia, Volkswagen e Toyota

As pessoas com deficiência visual, em sua maioria, ao aprenderem a leitura do Braille, são apresentadas ao alfabeto "padrão", geralmente utilizado em caixa alta e na versão simplificada, sem serifas. Contudo, não são estimulados a conhecer as variações anatômicas e formais tipográficas das letras. A simples reprodução dos tipos (letras) do alfabeto "padrão" não permite o entendimento e reconhecimento das variações estilísticas e formais das famílias tipográficas.

Quando contemplamos uma obra de arte, por exemplo, ativamos todo um sistema de gramática visual que nos leva a reconhecê-la como tal. O mesmo acontece ao design gráfico, mais especificamente, ao uso de tipografia para representação conceitual de algo. Quando olhamos o uso de uma fonte tipográfica com formas mais curvilíneas, com uso de contrastes, ou com serifas, certamente teremos uma noção de significado diferente daquela fonte que utiliza retas, não possui serifas e não apresenta variação de espessura.

Para uma pessoa com deficiência visual existem desafios que devem ser superados afim de que se faça entender as nuanças e os significados das formas em logotipos ou fontes.

Sabemos que não se trata apenas de descrever o "desenho" daquele símbolo ou logotipo, ou dizer o nome da empresa, mas fazer entender os conceitos que estão embutidos no uso das fontes aplicadas para representar graficamente aquela determinada marca.

Para tanto, entende-se a necessidade de apresentar às pessoas cegas ou com baixa visão, a anatomia ou as principais nuanças gráficas das famílias tipográficas, por meio da prototipação de um "sistema tipográfico tátil de placas" que apresentem e revelem tais nuanças.

\section{Um breve histórico das fontes}

As fontes escolhidas para o desenvolvimento da pesquisa inicialmente foram: Garamond (Old Style) e Helvetica (Linear). A escolha se deu tanto por serem marcos na história da tipografia desde o seu princípio, quanto por diferenças anatômicas significativas entre os tipos.

O sistema de classificação tipográfica utilizado é o criado por Maximilien Vox (Kane, 2003). Esta classificação se baseia em contextos históricos e características marcantes de cada tipo de modo a criar um estilo tipográfico.

O início da tipografia ocidental se deu no século XV com a primeira impressão de tipos móveis: a bíblia de Gutenberg. A composição foi feita com tipos que imitavam a textura, um estilo de caligrafia gótica.

$\mathrm{Na}$ segunda metade do século $\mathrm{XV}$, surgiu o chamado old style, tipografias baseadas na caligrafia humanista italiana para os tipos em caixa-baixa, e nas inscrições romanas para os tipos em caixa-alta.

No século XIX, tipos classificados como mecanicista ou de serifa quadrada foram criados durante a revolução industrial. $\mathrm{Na}$ época, existia a necessidade de tipos voltados para a impressão comercial, que tivessem mais impacto e que pudessem ser produzidos em larga escala com peças para grandes formatos. Por esta razão também foram amplamente utilizados os tipos móveis em madeira.

Já no século $X X$ se consolidam os tipos sans serif, ou lineares. Nesta época, em muitos países da Europa, estavam em voga movimentos minimalistas geométricos que buscavam a simplificação extrema, o que é percebido claramente na arquitetura e nas artes. Esse padrão também pode ser encontrado na tipografia, pela retirada das serifas, pela ausência de eixo e pela diminuição ou retirada completa do contraste nos tipos.

\section{Anatomia e termos técnicos}

No campo da tipografia há vários termos que visam determinar e classificar os tipos de modo que exista a compreensão clara de cada elemento. O estudo da anatomia no campo da tipografia se refere às partes de cada "glifo" fazendo uma referência ou metáfora ao campo das ciências da saúde, como pode ser visto nas Figura 2 e 3.

Especificamente para o presente artigo serão analisadas as características anatômicas das letras "a" maiúsculas e minúsculas nos tipos descritos anteriormente.

A letra "a" maiúscula apresenta como características: a presença de hastes, traço vertical mais marcante da letra; do ápice, união de duas hastes diagonais; e da barra, traço horizontal que une duas hastes. Nos glifos da Garamond existe ainda a presença de serifas, pé em ângulo reto ou oblíquo na extremidade do traço. Enquanto que na Helvetica as extremidades são compostas de terminais, ou seja, terminações de um traço sem serifa (Kane, 2003; Lupton, 2004).

Segundo Kane (2003), a letra "a" minúscula apresenta como características: a presença de olho, espaço vazio dentro de uma letra; de bojo, forma arredondada que define uma contraforma; e da espora, forma que articula a junção de um traço curvo e um retilíneo. Nos glifos da Garamond existe ainda a presença da lágrima ou terminal em gota, terminal arredondado de um traço sem ser a serifa. Já na Helvetica as extremidades são compostas de terminais.

Além das características dos glifos, existem também as características próprias de cada fonte. A Garamond se caracteriza por contraste entre traços, cantos arredondados, serifas, e pequena altura-x. Por outro lado, a Helvetica se 
caracteriza por não possuir contrastes, ter cantos retos, não possuir serifas nem grande altura-x.



Figura 2: Classificação tipográfica da Garamond e suas características

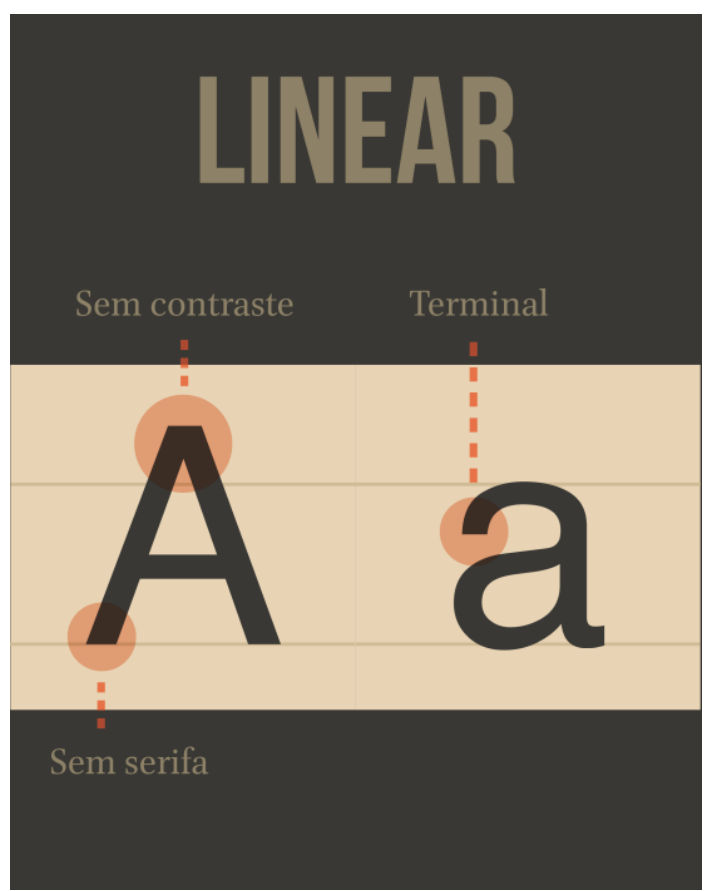

Figura 3: Classificação tipográfica da Helvetica e suas características

\section{Metodologia}

Com a intenção de se desenvolver uma proposta pedagógica que visa a identificação das características anatômicas e estilísticas das fontes tipográficas, para que as pessoas com deficiência visual possam compreender as nuanças, sutilezas e significados formais e históricos das fontes tipográficas, foram desenvolvidas peças tridimensionais das letras, de 250 pontos e com as principais características anatômicas dos estilos como pode-se ver nas Figuras 4 e 5.

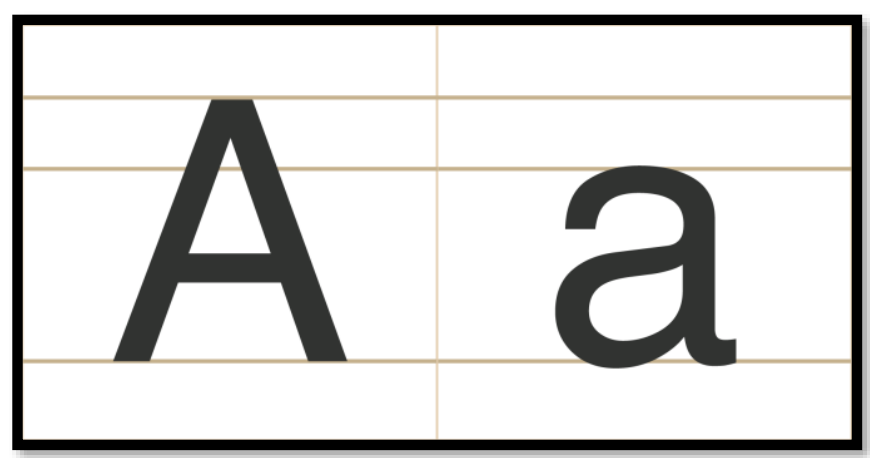

Figura 4: llustração de placa com as letras "a" da Helvetica

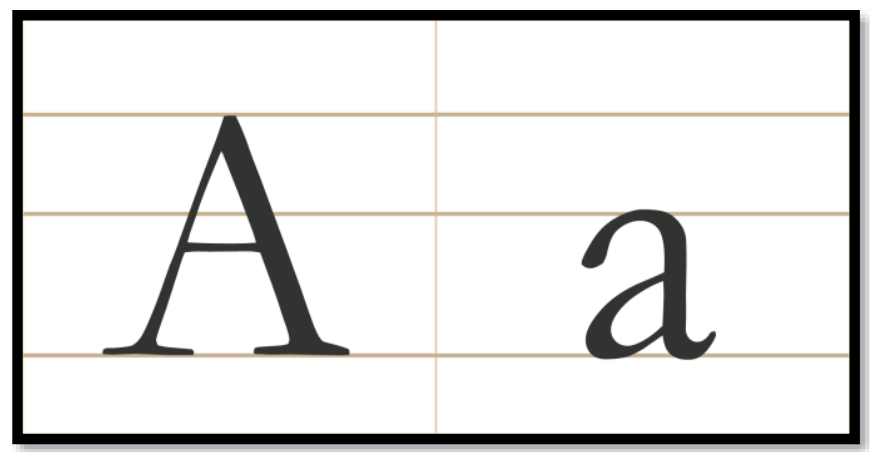

Figura 5: Ilustração de placa com as letras "a" da Garamond

Num segundo momento, foram aplicados testes com pessoas com algum tipo de deficiência visual e que fossem alfabetizadas:

Sujeito 1 - sexo masculino; deficiência visual parcial; faixa etária de 25 a 30 anos;

Sujeito 2 - sexo masculino; deficiência visual total adquirida por atrofia no nervo ótico há 26 anos; faixa etária de 45 a 50 anos.

\section{Procedimentos dos testes}

Os testes foram realizados em duas etapas, a saber:

Etapa 1 - Foram coletados dados como idade, escolaridade e tipo de deficiência. 
Etapa 2 - O entrevistado recebeu um conjunto de módulos táteis tridimensionais com as letras "a" maiúscula e minúscula com as tipografias classificadas como Helvetica e Garamond, produzidas por meio de máquina de prototipagem automatizada de subtração mostradas na Figura 6.

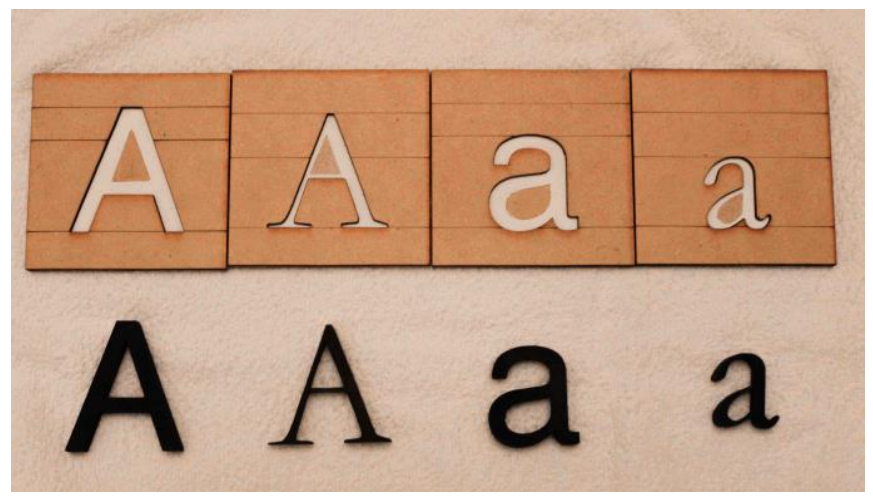

Figura 6: Placas com os tipos destacados

Após apalpar os módulos os entrevistados responderam algumas perguntas sobre as características desses módulos, enumeradas com base na classificação tipografia de Maximilien Vox acrescida de observações dos autores da pesquisa.

As características para as letras maiúscula e minúscula da Helvetica podem ser percebidas nas Figuras 7 e 8 . Tais características foram definidas como:

a. Sem serifas. Observa-se que serifas são constituídas por pequenos traços retos ou curvas localizadas nas extremidades das letras com o intuito de marcar os limites delas;

b. Tipografia sem contraste, ou seja, sem variação de traços grossos e finos;

c. Grande altura-x, ou seja, pequena diferença entre a altura da maiúscula e minúscula;

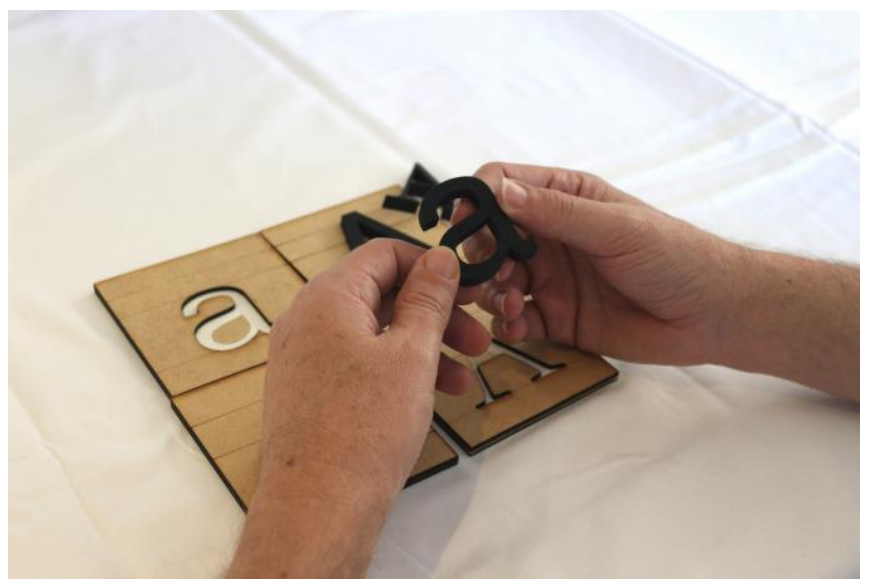

Figura 7: Letra "a" Helvetica minúscula sendo sentida

d. Cantos retos.

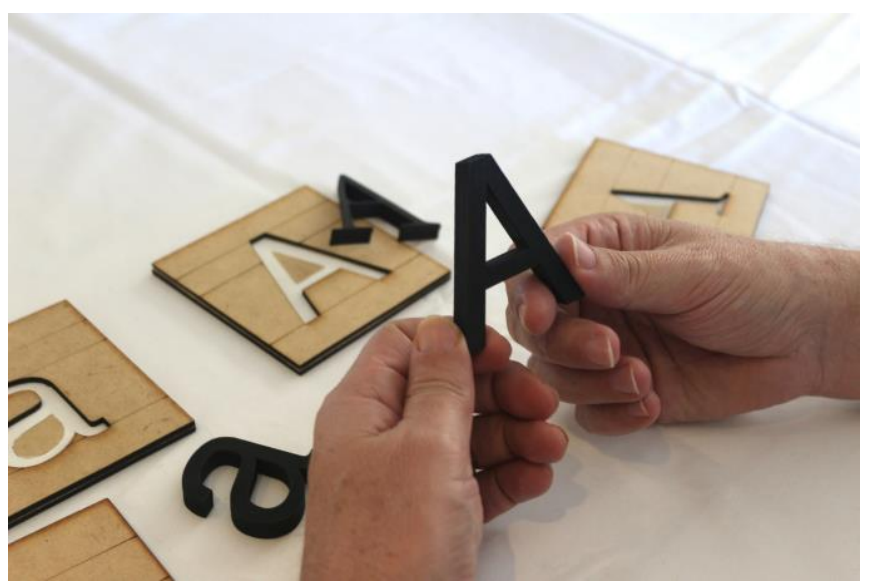

Figura 8: Terminais da letra "a" Helvetica maiúscula sendo sentida

As características para as letras maiúsculas e minúsculas da Garamond podem ser percebidas nas Figuras 9 e 10. Tal fonte deriva da escrita antiga feita com pena e tinta, além de ser intensamente utilizada para livros e textos de revistas, foram:

a. Pequena altura-x, ou seja, grande diferença entre a altura da maiúscula e a minúscula; 


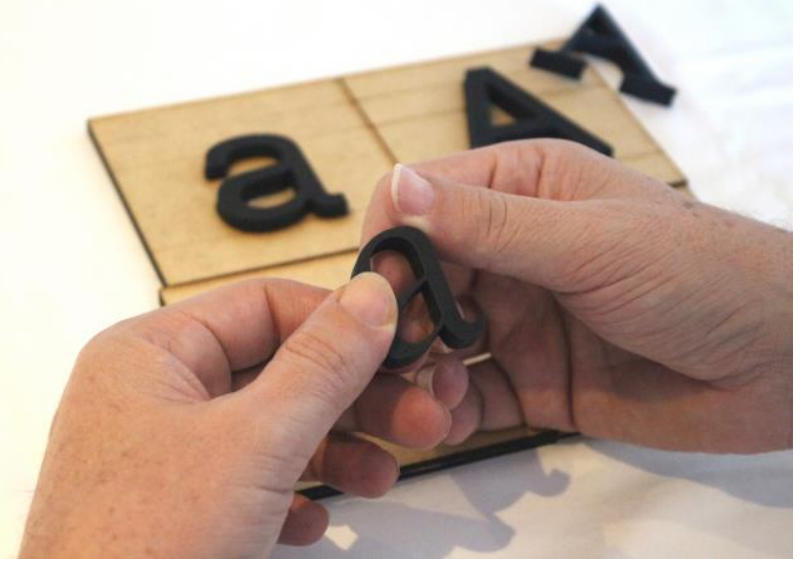

Figura 9: Letra "a" Garamond minúscula sendo sentida

b. Contraste acentuado entre traços finos e grossos;

c. Presença de serifas;

d. Cantos arredondados.

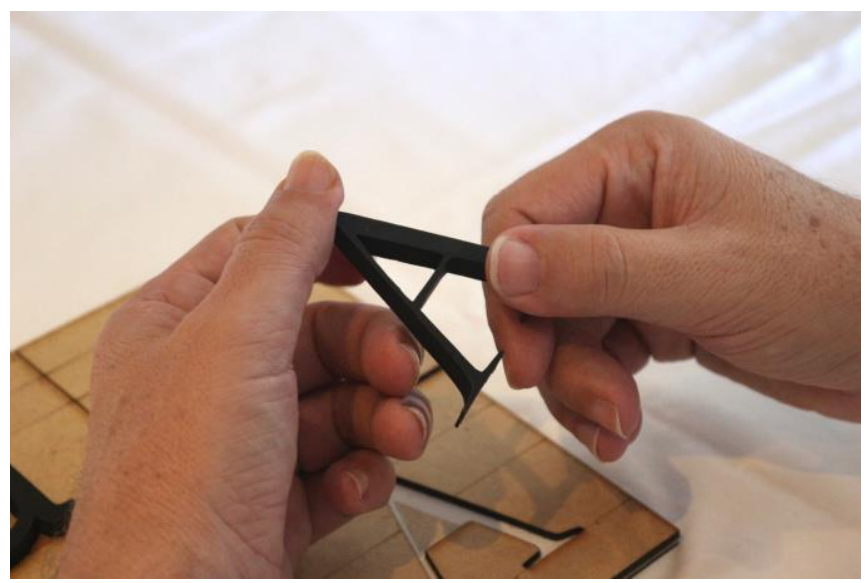

Figura 10: Serifa da letra "a" Garamond maiúscula sendo sentida

Ao entrevistado, foi perguntado se ele identificou cada uma das características das duas fontes tipográficas apresentadas. As respostas poderiam ser simplesmente sim ou não.

\section{Aplicação dos testes e resultados}

Os testes realizados obtiveram as seguintes respostas:

SUJEITO 1

Quanto à fonte Garamond:

a. Pequena altura-x: o sujeito identificou que há grande diferença entre a letra minúscula e a letra maiúscula,

b. Contraste acentuado entre traços finos e grossos: o sujeito identificou claramente as diferenças existentes entre as espessuras dos traços de cada letra

c. Presença de serifas: ficou muito clara a presença das serifas nas letras apresentadas; d. Cantos arredondados: o sujeito 1 teve dificuldades em identificar os cantos arredondados, principalmente em relação ao "a" maiúsculo.

Quanto à fonte Helvetica:

a. Sem serifas: não houve qualquer dúvida sobre a ausência de serifas por parte do sujeito 1 ;

b. Contraste: o sujeito 1 conseguiu identificar a ausência de contraste nas letras;

c. Grande altura-x: o sujeito 1 identificou claramente a pequena diferença entre a altura das letras minúscula e maiúscula;

d. Cantos retos: totalmente identificados.

\section{SUJEITO 2}

Quanto à fonte Garamond:

a. Pequena altura-x: o sujeito identificou que há grande diferença entre a letra minúscula e a letra maiúscula,

b. Contraste acentuado entre traços finos e grossos: o sujeito identificou claramente as diferenças existentes entre as espessuras dos traços de cada letra

c. Presença de serifas: ficou muito clara a presença das serifas nas letras apresentadas;

d. Cantos arredondados: claramente identificados.

Quanto à fonte Helvetica:

a. Sem serifas: não houve qualquer dúvida sobre a ausência de serifas por parte do sujeito 2;

b. Contraste: o sujeito 2 conseguiu identificar a ausência de contraste nas letras;

c. Grande altura-x: o sujeito 2 identificou claramente a pequena diferença entre a altura das letras minúscula e maiúscula;

d. Cantos retos: totalmente identificados.

$\mathrm{Na}$ realização dos testes, ficou evidente que o sujeito 1 (deficiência visual parcial) não conseguiu identificar uma das características que foram examinadas: os cantos arredondados da fonte Garamond. Já para o sujeito 2, não houve essa dificuldade.

Podemos creditar essa dificuldade do sujeito 1 a duas situações: a primeira tem relação à sua deficiência (deficiência visual parcial), ou seja, o sujeito não tem o sentido "tato" totalmente desenvolvido para a leitura; a segunda é que, para esse tipo de grau de deficiência, os detalhes das letras têm de ser ainda mais colocados em evidência, ou seja, a escala da fonte têm de ser aumentada.

Já o sujeito 2 respondeu positivamente para todas as afirmações de ambos os tipos, ou seja, percebeu todas as características propostas.

\section{Conclusão}

O desafio de encontrar caminhos para uma abordagem pedagógica do ensino do design, mais especificamente, da tipografia, às pessoas com deficiência visual, esbarra na premissa de que é necessário que na "experiência" aconteça a produção de sentidos e o entendimento técnico e poético. 
A impressão dos módulos com a tipografia permitiu aos entrevistados a correta identificação dos principais detalhes da anatomia dos tipos, levando, assim, ao entendimento daquilo que se quer alcançar: a forma dos tipos, seus significados e usos, e sua classificação.

A partir do entendimento da classificação, há a possibilidade do reconhecimento da forma dos tipos enquanto derivações de estilos.

\section{Agradecimentos}

Agradecemos aos participantes dos testes e à Associação Brasiliense de Deficientes Visuais - ABDV, por sua disponibilidade, e ao Prof. Francisco Aviani por sua orientação e apoio.

\section{Referências}

BRASIL. Decreto no. 5.296, de 2 de dezembro de 2004. Regulamenta as leis no. 10.048 , de 8 de novembro de 2000, que dá prioridade de atendimento 'as pessoas que especifica, e no. 10.098, de 19 de dezembro de 2000, que estabelece normas gerais e critérios básicos para a promoção de acessibilidade das pessoas portadoras de deficiência ou com mobilidade reduzida, e dá outras providências. Diário Oficial da União. Brasília, 2004.

Bringhurst, R. \& Stolarski, A. (2005). Elementos do estilo tipográfico. São Paulo: Cosac Naify.

Kane, J. (2003). A type primer. Upper Saddle River, NJ: PrenticeHall.

Lupton, E. (2004). Thinking with type. New York: Psrinceton Architectural Press.

Rocha, C. (2012). Novo projeto tipográfico. São Paulo: Rosari. 